\title{
Seven Foundational Principles of Population Health Policy
}

\author{
Dru Bhattacharya, JD, MPH, LLMํํㄹ and Jay Bhatt, DO, MPH, MPA, FACP²
}

\begin{abstract}
In 2016, Keyes and Galea issued 9 foundational principles of population health science and invited further deliberations by specialists to advance the field. This article presents 7 foundational principles of population health policy whose intersection with health care, public health, preventive medicine, and now population health, presents unique challenges. These principles are in response to a number of overarching questions that have arisen in over a decade of the authors' collective practice in the public and private sectors, and having taught policy within programs of medicine, law, nursing, and public health at the graduate and executive levels. The principles address an audience of practitioners and policy makers, mindful of the pressing health care challenges of our time, including: rising health-related expenditures, an aging population, workforce shortages, health disparities, and a backdrop of inequities rooted in social determinants that have not been adequately translated into formal policies or practices among the key stakeholders in population health. These principles are meant to empower stakeholders-whether it is the planner or the practitioner, the decision maker or the dedicated caregiver-and inform the development of practical tools, research, and education.
\end{abstract}

Keywords: population health, evidence-based care, current trends

\section{Introduction}

$\mathbf{I}^{\mathrm{s}}$ N 2016, KEYES AND GALEA issued 9 foundational principles of population health science and invited further deliberations by specialists to advance the field. ${ }^{1}$ This article presents 7 foundational principles of population health policy whose intersection with health care, public health, preventive medicine, and now population health, present unique challenges. For practitioners trained in public health, formal graduate training in accredited schools or programs of public health have included mandatory coursework in health services administration, but the content of these courses has varied significantly. Only recently has the accrediting body of schools and programs in public health changed the general requirements to now emphasize competency-driven education, though the precise nature and scope of content as relates to policy remains inadequate, particularly for students and practitioners in health care. The elusive distinction of public health and the clinical sciences also has contributed to this knowledge gap, emphasizing population and individual points of emphasis and care, though real-world practitioners often find themselves straddling the 2 universes. After the passage of the Patient Protection and Affordable Care Act, and the valuation of a preventive paradigm, along with specific requirements for 501(c)(3) entities to conduct community health needs assessments, this dichotomy of prevention and treatment, or individual versus population considerations, seems inadequate (if not unnecessary). Even the historical characterization of prevention across primary, secondary, and tertiary lines blurred the boundaries (an issue that will be revisited in this article), and only reifies our collective want for a more focused population health policy agenda.

The 7 foundational principles are in response to a number of overarching questions that have arisen in more than a decade of the authors' collective practice in the public and private sectors, and having taught policy within programs of medicine, law, nursing, and public health at the graduate and executive levels. These questions include: (1) What is population health policy? (2) What aspects of prevention should population health policy prioritize? (3) How is population health policy developed? (4) Should population health policy be uniform? (5) What standards should be used to measure the effectiveness

\footnotetext{
${ }^{1}$ Department of Population Health Sciences, University of San Francisco, San Francisco, California.

${ }^{2}$ Northwestern Memorial Hospital, Chicago, Illinois.
}

(C) Dru Bhattacharya and Jay Bhatt 2017; Published by Mary Ann Liebert, Inc. This article is available under the Creative Commons License CC-BY-NC (http://creativecommons.org/licenses/by-nc/4.0). This license permits non-commercial use, distribution and reproduction in any medium, provided the original work is properly cited. Permission only needs to be obtained for commercial use and can be done via RightsLink. 
of population health policy? (6) How should population health policy be evaluated? And (7) How does population health policy inform population health management?

The principles address an audience of practitioners and policy makers, mindful of the pressing health care challenges of our time, including: rising health-related expenditures, an aging population, workforce shortages, health disparities, and a backdrop of inequities rooted in social determinants that have not been adequately translated into formal policies or practices among the key stakeholders in population health. ${ }^{2}$ These principles are meant to empower stakeholders-whether it is the planner or the practitioner, the decision maker or the dedicated caregiver - and inform the development of practical tools, research, and education.

\section{What is population health policy?}

\section{Principle 1}

Population health policy includes directives, plans, and courses of action that may be required by law or developed in compliance thereto, or proffered voluntarily, documented in written instruments or manifest in norms and behaviors sanctioned through customary practice without objection.

Definitional clarity on what a policy is comprised of, and how it manifests or arises in practice, is desirable for purposes of planning, implementation, and evaluation. The Public Health Institute defines a policy as "a rule or set of rules that people must follow," and does not make any distinction between legal and nonlegal instruments or the forms in which they manifest in practice. ${ }^{3}$ The Centers for Disease Control and Prevention (CDC) defines policy as "a law, regulation, procedure, administrative action, incentive, or voluntary practice of governments and other institutions." 4 This definition is inadequate because it does not explicitly recognize the role of planning, and specifically those particular instruments (eg, strategic plans) that may not be required under law, but contains critical elements that include the organization's identity-namely, its vision, mission, and values-along with its short- and long-term priorities. Moreover, policy is not always documented in written form, and may even manifest in norms and behaviors at an individual level that have become legitimized through silent acquiescence within professional circles. There may be valid reasons for doing so; for example, out of respect for the discretion afforded patients and their families regarding decisions for which there is legal or ethical ambiguity, or for which the hospital may not wish to draw public scrutiny. None of these reasons, however, necessarily divest the entity of its potential moral or legal culpability, but absolutely allow for the potential to engage in wasteful expenditures, unpredictable decision making, and a lack of transparency that might compromise quality of care. Explicit recognition of these elements only enhances the opportunity for engagement with other private or public entities, thereby enhancing a culture of population health where the semblance of absolute control or authority on an issue is neither necessary nor helpful. Although the express documentation of a policy is preferred, the absence of documentation does not make a pervasive practice any less of a policy.
What aspects of prevention should population health policy prioritize?

\section{Principle 2}

Population health policy prioritizes early detection, treatment, and mitigation of, and rehabilitation following, disease among at-risk and symptomatic individuals.

Leavell and Clark's tripartite classification scheme across primary, secondary, and tertiary levels of prevention was a landmark in denoting preventive responses to different stages of disease susceptibility from general prevention within the population, to select measures among at-risk individuals, to targeted responses toward those afflicted with illness, respectively. ${ }^{5}$ Ever since, there has even been a general consensus on the scope of primary prevention, but far more variability in the characterization of secondary and tertiary prevention. ${ }^{6}$ Where secondary prevention has included treatment, and tertiary prevention has included nonmedical service delivery in outpatient settings (eg, physical therapy, home health), the effort to incorporate a comprehensive preventive paradigm for a single health care entity does not facilitate strategic planning and operations. With $33.8 \%$ of health care expenditures directed toward hospital care, $21.0 \%$ for physician services, $10.3 \%$ for prescription drugs, and $8.3 \%$ for nursing home care and home health, an emphasis on early detection and treatment, along with rehabilitation and disease management, is imperative. ${ }^{7}$ Moreover, the public health system has been chronically underfunded with limited funds directed to carry out core preventive functions. ${ }^{8}$ Novel perspectives have been put forth in how to integrate protective factors or separate out levels of exposure as relates to its acquisition and the onset of disease progression. These epidemiological inquiries are important, but prioritization is not a uniquely epidemiological problem, implicating ethical, economic, legal and, at times, political considerations. Kindig popularized the term population health in the United States, but noted that public health agencies are trying to emerge into a fuller role and assuring health outcomes at a population level, but are far from this vision in practice. ${ }^{9}$ His observation was not meant to belittle public health agencies, but to temper the idealism with the realistic constraints of operational incentives and considerations. Therefore, emphasis is given here to early detection and targeted interventions that demand assessment of pressing unmet health needs, identification of vulnerable populations, treatment of symptomatic individuals, and their concomitant health needs through rehabilitation. Prevention is central to this principle, but operates with more predictability and, hence, opportunity for a sustainable population health policy.

\section{How is population health policy developed?}

\section{Principle 3}

The development of population health policy is the product of political, economic, epidemiological, ethical, behavioral, and legal considerations and their covariations.

There are distinct processes that may govern the development of policy in public and private sectors, yet the 
common levers are invariably and ubiquitously present, if not explicitly implicated. These intersections within public health have been previously explored and are pervasive within and across organizational settings. ${ }^{10,11}$ Moreover, these forces have shaped the development of public and institutional policy, at times in a singular, but more often a composite manner. The passage of the Affordable Care Act was as much a product of political expediency as an ethical endeavor to extend care to the uninsured. Improving quality is as much an economic consideration as an epidemiological or ethical one. In government, the authority for policy development may take different forms, from legislative mandates to regulatory actions, public educational campaigns, or even a court decision, all of which may involve a myriad of actors, including the legislative, executive, and judicial branches. In a hospital, the institutional dynamics are not as publicly transparent, but are certainly viable in policy committees, the processes by which they are constituted, and the charges with which they prioritize institutional positions. The absence of uniform guidelines for hospital policy making, notwithstanding the appropriateness of such guidelines, coupled with the inevitable (and perhaps unintentional) implications for population health policy, require a concerted effort to at least establish policy where failure to do so may be interpreted as acquiescence in certain behaviors or conduct. Hospitals may have standing policy committees that issue formal policies that are topically specific, such as adverse reactions to medications, records management, or transfer of patients. Winkler has identified 5 procedural and substantive requirements a policy-writing process should meet to deal with moral disagreement on controversial medical practices, which may be paraphrased as stakeholder representation, deliberation on all of the organization's obligations, an explicit rationale, avenue for critique, and evaluation. ${ }^{12}$

The present proposed framework encompasses these criteria, but places heightened emphasis on highlighting the structure and processes governing the election, composition, and functioning of the deliberating body or committee, an explicit accounting of the evidence base rooted in the epidemiological literature, the economic and financial context, and the legal constraints and opportunities. It also includes behavioral health considerations, given the breadth of emerging programs that have proven critical to population health success. In 2014, approximately 43.6 million adults (18.1\%), ages 18 years and older, experienced a serious mental illness, and an estimated 2.8 million youths, ages 12 to 17 years, had a major depressive episode within the past year. ${ }^{13}$ One in 10 Americans used an illicit drug in the past 30 days, $13.0 \%$ of adolescents were current cigarette smokers, and estimates of binge drinking among individuals-23.0\% among individuals, ages 12 years and older-has not changed since 2002. ${ }^{13}$ Against this backdrop, behavioral health should be a foundational core strategy for any population health program in an integrated delivery system. ${ }^{14}$

The population health implications of these considerations are also distinguishable insofar as they do not end with a determination of the appropriate standard of care, but rather begin anew with the potential future engagementevinced by the policy statement itself_-in relation to other public or private statements on the same. Here, the population health policy may inform clinical practice but wel- comes societal critique and evaluation in addition to, if not apart from, institutional evaluation.

Should population health policy be uniform?

\section{Principle 4}

The heterogeneity of population health needs among groups of individuals across different demographics and jurisdictions requires the development of population health policy that balances the standardization and customization of interventions.

Uniformity may or may not be necessary or sufficient, yet it is not the potential pervasiveness of policies but rather the absence of evaluation thereof that is particularly troublesome. There have been more than 100 model health laws published since the beginning of the 20th century, yet Hartsfield et al undertook a study and found that only 18 of 107 sponsors $(16.8 \%)$ presented any information on the procedures and evidence used in developing their model public health laws, and no information on their effectiveness. ${ }^{15}$ The adoption of some model policies in formal laws or best practice guidelines may facilitate national discourse and build momentum for federal policy making, or perhaps streamline resources in affected states or institutions. However, if public health is local, population health must be localized, inevitably requiring a bottom-up assessment and the attendant customization of interventions to address the specific needs of high-risk and vulnerable populations. These needs often become characterized in the context of health disparities, but addressing them from a population perspective requires a multilevel approach that combines population, clinical, and basic sciences. ${ }^{16}$ In 2015 , residents of Flint, Michigan, complained of a discoloration and pungent odor emanating from the water after the town switched its water supply, followed by a spike in rashes and eye irritations. Pediatrician Mona Hanna-Attisha compared the lead levels in samples taken before and after the switch and discovered that the percentage of children with lead poisoning had doubled. Notably, state health officials had engaged in fraudulent conduct, denying the results, and a Congressional stalemate prevented millions of dollars in federal aid until September 2016. This incident highlights 2 critical tenets of this principle. First, the relevant population health policy here is not limited to the existing public health (in)action, and the pervasive regulatory landscape, both of which did nothing to address the problem. Rather, it was Dr. HannaAttisha's efforts, and the institutional support of her hospital, Hurley Medical Center, that enabled her to sort through its own medical records-1746 test results from Flint's children-against the 1640 results elsewhere in the county that yielded the sobering results. ${ }^{17}$ The hospital, perhaps unwittingly, had committed itself to its own policy under the blunt directive of Hurley chief executive officer Melany Gavulic that kids' health comes first, and whose role was perhaps underreported in public press, but well noted by Dr. Hanna-Attisha, describing her as one of the hospital's superstars.

The course of action taken by Dr. Hanna-Attisha and her colleagues, explicitly sanctioned and supported by her institution, was customized to the needs of a vulnerable 
subgroup-namely, impoverished children at heightened risk for lead poisoning - under the broader mandate of prioritizing children's health. In doing so, this example illustrates how communities and public health agents can shape the research, make it relevant to communities, and contribute to the reduction in health disparities. Uniformity in population health policy may be desirable at times, but may be neither necessary nor sufficient (or even feasible) for addressing a pressing population health need.

What standards should be used to measure the effectiveness of population health policy?

\section{Principle 5}

Determination of the effect of population health policy, insofar as it creates or does not impede the exercise of rights, duties, or privileges associated with outcomes, must also take into account the status, and effect, of social determinants of health.

Targeted interventions may yield improved outcomes with no modification of determinants of health affecting broader population health needs. This is distinguishable from the proposition that efforts to improve overall population health may be a disadvantage to some groups on the basis of prioritizing equity or efficiency. Here, the authors draw attention to indicators that may be removed from traditional epidemiological analyses and ought to be included, pursuant to a broader social epidemiological profile of an affected population, and measured with the appropriate local indicators. In conjunction with the CDC, Hillemeier et al issued a data set directory of social determinants of health at the local level across 12 dimensions, including the economy, employment, education, political, environmental, housing, medical, government, public health, psychosocial, behavioral, and transport. ${ }^{18}$ Within each domain are components and specific indicators that may be used to measure these broader determinants of health. Notably, the classification of a group of indicators constituting "public health" as a distinct dimension of social determinants of health with a narrow focus on its programs, enforcement of regulations, and funding, only reifies Kindig's claim that government health agencies are currently constrained by their explicit charges and operational needs, neither of which ought to detract from their commitment and role in securing population health.

The breadth of these dimensions, however, amplifies the pervasiveness of social determinants beyond the jurisdiction of a single agency of government or all of government for that matter, implicating the role of private actors, the potential need for public-private partnerships, and the attendant policies to alleviate the burden of illness on a population. In practice, the utilization of social impact bonds (SIBs), for example, are a testament to this ever-changing landscape, and notwithstanding the ethical implications of these measures, certainly speaks to the role of private organizations working with public health agencies to generate costs savings and promote health outcomes. SIBs are simply a financing mechanism that utilizes loans from an investor provided to an organization (ie, intermediary) that contracts with a nonprofit to administer services that generate significant cost savings for the government, which otherwise would foot the bill of costs associated with unrealized gains in health or improvement in health-related indicators. Upon realization of those improved outcomes, the government pays the investor a percentage of its anticipated cost savings, which are estimated and secured through a formal contract executed between the government and the investor. Examples have included projects intended to reduce recidivism, homelessness, at-risk youth service, and workforce development, among others. Given the novelty of these arrangements (at least within the United States), there is no general consensus on their effectiveness, but in practice, they are potentially capable of addressing social determinants, which ought to be part of a broader population health policy agenda.

In a global context, US spending on social services constitutes a small share of the economy relative to other developed countries, with notable disparities in poorer health outcomes, shorter life expectancies, and a greater prevalence of chronic conditions. ${ }^{19}$ Notable examples within the United States include the Brookline Early Education Project (BEEP), which was a community-based program that provided health and developmental services for children and families from 3 months prior to birth through kindergarten. A follow-up study that examined program participants in comparison to nonparticipant peers found that BEEP participants in urban communities had advantages over peers in educational attainment, income, health, and well-being. ${ }^{20}$

By highlighting and prioritizing initiatives that secure social services with attendant health benefits, public officials may begin to effectively balance expenditures between health care and social services.

\section{How should population health policy be evaluated?}

\section{Principle 6}

The evaluation of population health policy includes both normative and empirical inquiries that may be applied to all of its component considerations and their covariations.

Although epidemiology may be characterized as the science of public health, this principle rejects the notion that empirical analysis for population health policy is unique to epidemiology and that normative inquiry is unique to law and ethics. There has been an ever-increasing body of empirical population health research in other disciplines, including methodological compendiums and novel frameworks in areas of public health law, and population and public health ethics. ${ }^{21}$ Recent studies highlighting the potential of empirical health law research include the evaluation of retailer compliance with a cigar packaging and pricing regulation in Boston, Massachusetts, and its impact on the availability of single cigars. ${ }^{22}$ Another study assessed how nonmedical exemption laws and annual uptake of vaccines required for school or day care entry affect annual incidence rates for 5 vaccine-targeted diseases. ${ }^{23}$ In the domain of ethics, the integration of empirical and population-level inquiry is quite novel, and has not generated as many formal studies as its legal counterpart.

Knight proposed a definition regarding empirical public and population health ethics as the active integration of individual and population-level empirical research and normative analysis of the generated data regarding a moral issue, followed by a normal conclusion. ${ }^{24}$ He suggested the expansion 
of individual-level interactions, for which there is an established literature, to focus on how policy responds to various population subgroups with respect to a population health moral issue (eg, equity, social justice).

Epidemiology has historically secured its place within public health science because of its utility as a tool for the assessment of risk. From the formulation of hypotheses to the selection of study populations and indicators of exposure, followed by the measure and analysis of the relationship between exposures and disease, the ultimate aim is to inform risk assessment and attendant interventions to reduce risk among populations exposed or at risk of being exposed to the factor(s) under investigation. Yet, as Cranor has eloquently argued, the very idea of risk assessment has many normative presuppositions that ought to give us pause in how we characterize epidemiological inquiry. ${ }^{25}$ Among those presuppositions is that risk assessment is normatively laden, given that risk is simply the probability of an undesirable outcome - from an a priori evaluative view. Secondly, it is imperfect because of its basis in probability, with the inevitability of mistakes so that reducing the costs of mistakes may be a particular goal. Yet, social costs implicate more than money alone, and thus suggest an additional evaluative point of view to reinforce the normative point. Additionally, and perhaps most relevant to this discussion, is his observation that the practices and conventions within a field may inadvertently predispose procedures to certain outcomes, frustrating other goals (eg, identifying risks to subgroups or the environment). This is particularly relevant when one is hoping to direct resources to alleviate the burden of illness on vulnerable populations, which requires a robust assessment of determinants that may not be reflexively captured by the traditional demographic breakdown in an epidemiological profile (eg, education, socioeconomic status, sex).

Consequently, we ought to engage in empirical and normative analyses in the planning, drafting, execution, and evaluation of population health policies and not restrict those inquiries to particular disciplines. In doing so, we enhance the potential contributions that may afford further insight into causes, considerations, and perhaps covariations among factors across different fields of inquiry. This is not an attempt to highlight the invocation of potential confounders in response to a typical observational study, but to emphasize that the traditional characterization of epidemiology is actually the study of clinically-oriented determinants of health. For stakeholders in population health policy, the tool kit of empirical and normative evaluative measures is not, and should not be, confined to a single discipline.

How does population health policy inform population health management?

\section{Principle 7}

The management of population health requires alignment between organizational strategic planning and the strategic management of human resources, with the population health needs identified through available health needs assessments and input from affected population members.

The precise alignment of policy and management is as much an iterative enterprise as a linear course of events and functions. By implementing and evaluating policies, we may obtain insights into gaps and opportunities for amending, enacting, or even repealing particular (or entire) measures that are not achieving the desired outcomes. This principle operationalizes this synergy between policy and management, beginning with the alignment of an organization's priorities and the population health needs based on a health needs assessment. Organizational priorities are evinced in formal strategic plans and the attendant strategic management of human resources. By articulating the vision, mission, and values, along with a set of goals and objectives, an organization facilitates subsequent performance evaluation by its own leaders and managers, along with potential and existing external collaborators and partners.

The strategic management of human resources is an often neglected, yet critical, piece that speaks to the precise alignment of individuals with the organization, specifically as a function of their ability to engage the strategic plan and sustain productivity through timely incentives as relates to their personal and professional goals. Transparency in processes and directives does not automatically translate into an engaged workforce, and the latter is not a matter of mere negotiation on issues of salary and benefits. Organizational growth, particularly as relates to the quality of goods or services provided, is stymied by hierarchical models of management, the absence of ownership (and the resulting disempowerment) among employees, and the lack of incentives, which tempers the capability to respond to negative incidents or trends. Its corollary, however, is also true where growth is driven by individual creativity that is best served by a culture of respect, responsibility, and resilience. Ironically, the one factor that health professionals often seek to reduce at the individual level-risk-is what often is required for the organization's growth in the aggregate. Risks in the health care context are inherently bad, contrasted with benefits, and are among those binary characterizations that make for an easy checklist of advantages and disadvantages, perhaps best captured in the doctrine of informed consent. Subscribing to one course of treatment has inherent benefits marked by improved health outcomes and some inherent risks that we hope to minimize or avoid-but with the understanding that choosing no treatment will only exacerbate the problem. For the organization, however, risk is a vehicle of transformation, which is how leadership manifests itself in elevating long-term performance. Barr et al introduced the "expanded" Chronic Care Model to explicitly integrate strategies from population health promotion and cited organizational change alongside legislation, fiscal measures, and taxation among complementary approaches to improve population health, and specifically prevent and manage chronic diseases. ${ }^{26}$ Decade-old lessons from an analysis of the Mayo Clinic by Berry and Seltman are just as relevant today as they were in 2007 when they found that adherence to organizational values, playing defense (not just offense), and turning customers into marketers had created a strong services brand for this preeminent health care organization. ${ }^{27}$ These characteristics are by-products of a system that has successfully aligned its organizational values with the strategic management of its human resources. For health systems that have not adopted a population health perspective, organizational change is imperative to effectively manage and implement population health policy. 


\section{Conclusion}

In summary, these proposed foundational principles of population health policy respond to 7 pressing issues that have never been adequately addressed, let alone resolved, in policy circles. These principles respond to these issues with guidance to demarcate the potential breadth and depth of a new population health policy agenda. This article has articulated a domain of population health policy, informed by and consistent with the foundational population health principles espoused by Keyes and Galea, yet tailored to the particular needs of individuals positioned to craft, implement, and evaluate policy. These principles are meant to empower stakeholders and generate further work in the development of practical tools, research, and education that may inform their particular utility in specific contexts.

\section{Author Disclosure Statement}

Prof. Bhattacharya and Dr. Bhatt declared no conflicts of interest with respect to the research, authorship, and/or publication of this article. The authors received no financial support for this article.

\section{References}

1. Keyes KM, Galea S. Population health science. New York: Oxford University Press, 2016.

2. Petterson SM, Liaw WR, Phillips RL, Rabin DL, Meyers DS, Bazemore AW. Projecting US primary care physician workforce needs: 2010-2025. Ann Fam Med 2012;10:503-509.

3. Public Health Institute. Fact Sheet-What Is Policy? 2009. www.phi.org/uploads/application/files/qqpnls4ewtm2497t8 tdfjfhq0xv7dvjr5m2n7be851mytc9emh.pdf Accessed October 12, 2016.

4. Centers for Disease Control and Prevention. Public Health Policy. November 9, 2015. www.cdc.gov/stltpublichealth/ policy Accessed October 12, 2016.

5. Leavell HR, Clark EG. Preventive medicine for the doctor in his community; an epidemiologic approach, 2nd edition. New York: McGraw-Hill, 1958.

6. Froom P, Benbassat J. Inconsistencies in the classification of preventive interventions. Prev Med 2000;31:153-158.

7. American Hospital Association. Trendwatch Chartbook 2016. 2016. www.aha.org/research/reports/tw/chartbook/2016/ chapter1.pdf Accessed October 12, 2016.

8. Levi J, Segal LM, Gougelet R, Laurent RS. Investing in America's Health: A State-by-State Look at Public Health Funding and Key Health Facts. 2015. http://healthyamericans .org/assets/files/TFAH-2015-InvestInAmericaRpt-FINAL.pdf Accessed November 14, 2016.

9. Kaufman NJ, Kindig DA. Public Health vs. Population Health: A Conversation. October 1999. https://uwphi.pophealth.wisc .edu/about/advisory/public-vs-population-health-conversation .pdf Accessed October 12, 2016.

10. Bhattacharya D. Public health policy: issues, theories, and advocacy. San Francisco, CA: John Wiley \& Sons, 2013.

11. Bhattacharya D, Bhatt J. Novel interprofessional collaborations: utilizing medical-legal partnerships to advance population health. In: Bhattacharya D, Callahan R, eds. Public health leadership. New York: Taylor and Francis, 2017:41-53.

12. Winkler EC. The ethics of policy writing: how should hospitals deal with moral disagreement about controversial medical practices? J Med Ethics 2005;31:559-566.
13. Hedden SL. Behavioral Health Trends in the United States: Results from the 2014 National Survey on Drug Use and Health. 2015. www.samhsa.gov/data/sites/default/files/ NSDUH-FRR1-2014/NSDUH-FRR1-2014.pdf Accessed November 14, 2016.

14. Letourneau R. Behavioral Health Programs Critical to Population Health Success. April 2015. www.healthleadersmedia .com/finance/behavioral-health-programs-critical-populationhealth-success\# Accessed November 14, 2016.

15. Hartsfield D, Moulton AD, Mckie KL. A review of model public health laws. Am J Public Health 2007;97(Suppl 1): S56-S61.

16. Warnecke RB, Oh A, Breen N, et al. Approaching health disparities from a population perspective: the National Institutes of Health Centers for Population Health and Health Disparities. Am J Public Health 2008;98:1608-1615.

17. Erb R. Young Doctor Takes on Flint Water Fight. October 11, 2015. www.usatoday.com/story/news/nation-now/2015/ 10/11/flint-water-doctor/73777352/ Accessed October 12, 2016.

18. Hillemeier M, Lynch J, Harper S, Casper M. Data Set Directory of Social Determinants of Health at the Local Level. 2004. www.cdc.gov/dhdsp/docs/data_set_directory.pdf Accessed October 12, 2016.

19. Squire D, Anderson C. U.S. Health Care from a Global Perspective: Spending, Use of Services, Prices, and Health in 13 Countries. October 2015. www.commonwealthfund .org/ /media/files/publications/issue-brief/2015/oct/1819_ squires_us_hlt_care_global_perspective_oecd_intl_brief_v3 .pdf Accessed November 14, 2016.

20. Palfrey JS. The Brookline Early Education Project. A 25year follow-up study of a family-centered early health and development intervention. Pediatrics 2005;116:144-152.

21. Wagenaar AC, Burris S. Public health law research: theory and methods. San Francisco, CA: Wiley, 2013.

22. Li W, Gouveia T, Sbarra C, et al. Has Boston's 2011 cigar packaging and pricing regulation reduced availability of single-flavoured cigars popular with youth? Tobacco Control 2016. DOI:10.1136/tobaccocontrol-2015-052619

23. Yang YT, Debold V. A longitudinal analysis of the effect of nonmedical exemption law and vaccine uptake on vaccinetargeted disease rates. Am J Public Health 2014;104:371377.

24. Knight R. Empirical population and public health ethics: a review and critical analysis to advance robust empiricalnormative inquiry. Health 2015;20:274-290.

25. Cranor CF. The normative nature of risk assessment: features and possibilities. Risk 1997;8:123.

26. Barr V, Robinson S, Marin-Link B, et al. The expanded chronic care model: an integration of concepts and strategies from population health promotion and the chronic care model. Hosp Q 2003;7:73-82.

27. Berry LL, Seltman KD. Building a strong services brand: lessons from Mayo Clinic. Business Horizons 2007;50: 199-209.

Address correspondence to: Dru Bhattacharya, JD, MPH, LLM Department of Population Health Sciences University of San Francisco 920 Old Mason Street San Francisco, CA 94129

E-mail: dbhattacharya@usfca.edu 